\title{
Inhalt
}

Vorbemerkung .............

Kurt Pätzold

Jahrhundertsicht in Peter Weiss' Roman „Die Ästhetik des Widerstands" ................

Wolfgang Schindler

Der Große Fries des Pergamonaltars - Peter Weiss' Deutungen in der Sicht des Klassischen Archäologen . . . . . . . .

\section{Irene Dölling}

Frauen im Klassenkampf - Klassenkampf und Geschlechterfrage in Peter Weiss' "Ästhetik des Widerstands“ . . . . . .

Karl-Hein $\chi$ Mauß

Die Psychologie des Widerstands - Gedanken zum Handlungskonzept von Peter Weiss . . . . . . . . . . . .

Norbert Krenzlin

Ästhetik im Epochenumbruch - Zur Stellung der „Ästhetik des Widerstands“ in den Ästhetik-Debatten der Gegenwart . .

Ursula Heukenkamp

Angelus novus oder der Erzähler in der „Ästhetik des Widerstands".................

\section{Harald Olbrich}

„Die Ästhetik des Widerstands" als Herausforderung: Zum Umgang mit bildender Kunst 


\section{Gudrun Klatt}

Korrespondenz und Widerspruch - Brecht bei Peter Weiss . . 135

Jürgen Kuttner

„... kein Buch, das einfach zum Leser gelangt“? - Zur Aufnahme der Ästhetik des Widerstands in der BRD . . . . . . 154

Anmerkungen ............... 177

Auswahlbibliographie . . . . . . . . . 204

Personenregister . . . . . . . . . . . 208

Zu den Autoren . . . . . . . . . . . . . . . . . . . 211 